Research article

\title{
New fluorescein dye derivatives and their use as an efficient photoiniator using blue light LED
}

\author{
Rafael Turra Alarcon, Caroline Gaglieri, Bruno Henrique Sacoman Torquato da Silva, \\ Luiz Carlos da Silva Filho, Gilbert Bannach*
}

São Paulo State University (UNESP), School of Sciences, Chemistry Department, 17033-260, Bauru, SP, Brazil

\section{A R T I C L E I N F O}

\section{Article history:}

Received 7 February 2017

Received in revised form 14 April 2017

Accepted 18 April 2017

Available online 23 April 2017

\begin{abstract}
A B S T R A C T
This work investigates the degree of conversion, thermal properties, and morphological features of polymers obtained using UDMA monomer and fluorescein and its derivatives dyes as photoinitiator. Photopolymerization has opened new research and material due to its synthesis ability as well as ecological and economic advantages. Fluorescein is a dye with great fluorescent properties; therefore, it could be used as initiator in photopolymerization, including its derivatives. Simultaneous Termogravimetry-Differential Thermal Analysis and Derivative Thermogravimetric (TG/DTG-DTA), Differential Scanning Calorimetry (DSC), Middle Infrared Spectroscopy (MIR), and Scanning Electronic Microscopy (SEM) were used to determine thermal properties, degree of conversion, and morphological characteristics of polymers obtained. The data show that the use of fluorescein and its derivatives as photoinitiators did not change the thermal stability of the polymer $\left(193.1_{3} \pm 7.9^{\circ} \mathrm{C}\right)$; however, the chlorinated dyes produced a better degree of conversion (78.73\% to F-2 and $69.36 \%$ to $\mathrm{F}-5$ ) than brominated dyes (21.18\% to F-3 and $1.21 \%$ to F-6), resulting in solid rigid polymers.
\end{abstract}

(c) 2017 Elsevier B.V. All rights reserved.

\section{Introduction}

Photopolymers are widely used in dentistry, with applications ranging from restoration material, sealing, and cementation for dental adhesives, as well as new materials, biomaterial, paints, coatings, optical materials, and composites [1-6]. Hence, photocuring techniques of polymerization is of great interest, due to its ease of synthesis, economic and ecological benefits, fast curing, low energy demand, ability to perform at room temperature, low toxicity, and relatively inexpensive cost, when compared to common thermal methods for polymerization [1,6-8]. Polymerization is triggered by initiators, which generate reactive forms (radicals) that attack the alkene in the monomer structure. The two-component (Type II) method is the most widely used, applying dye as initiator and coinitiators such as ethyl-pdimethylaminobenzoate (tertiary amine) $[9,10]$.

Fluorescein is a common and inexpensive dye that is widely used in fluorescents materials and paints. It has a high molar absorptivity, because protolytic reactions occur in the excited state

\footnotetext{
* Corresponding author.

E-mail address: gilbert@fc.unesp.br (G. Bannach).
}

[11-13]. Hence, this dye could be used as an initiator in photopolymerization, and some research has indicated its use in solar cells, chemical sensors to identify metallic ions, and new monomers [14-17]. This work shows new synthesis of fluorescein derivatives and their use as photoinitiators for polymerization.

To verify the extent to which polymerization occurs when using these new dyes, Middle Infrared Spectroscopy (MIR) and Differential Scanning Calorimetry (DSC) were used. Common thermo-analytic methods, such as Thermogravimetry (TG) and Differential Thermal Analysis (DTA), were conducted to compare the impact of different dyes on the thermal stability and other thermal events of the polymer. Derivative Thermogravimetry (DTG) was applied to the TG curve to better observe the thermal events on the assays. Finally, Scanning Electron Microscopy (SEM) was performed to analyze the morphological aspects of the polymers.

\section{Material and methods}

\subsection{Dyes synthesis}

All dyes used in this study were synthetized following the route described by Silva et al. [14], through the reaction between 


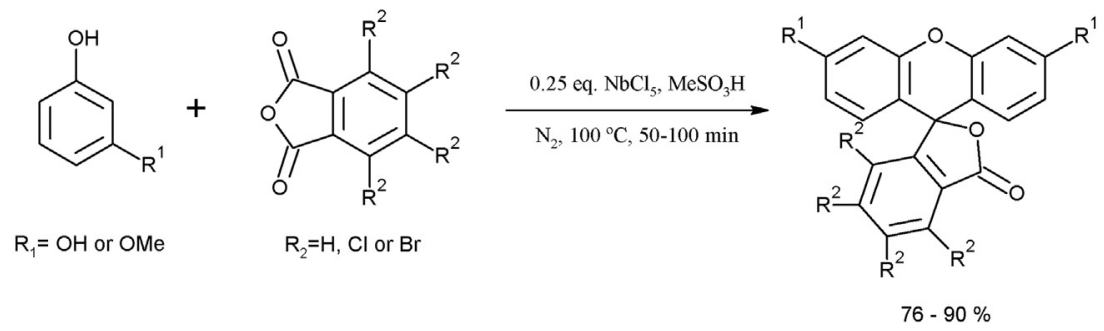

Fig. 1. Syntheses of fluorescein derivatives.

$2.0 \mathrm{mmol}$ of phenol derivatives with $1.0 \mathrm{mmol}$ of anhydride derivatives, under heating at $100^{\circ} \mathrm{C}$, using $\mathrm{MeSO}_{3} \mathrm{H}$ as solvent and 0.25 equivalent of $\mathrm{NbCl}_{5}$ as catalyst (Fig. 1).

\subsection{Preparation of the monomeric mixtures and photopolymerization}

For the preparation of the monomeric mixtures, UDMA (Urethane Dimethacrylate) (Aldrich) was added to six individual plastic containers, each with $0.01 \mathrm{~mol}$ of the monomer. The photoinitiating solutions were prepared by dissolving the respective dye (Fig. 2) and Ethyl-p-dimethylaminobenzoate in ethanol at a concentration of $20 \mathrm{mmol}$ of each reagent and added to the reaction mixture (UDMA) in the proportion of $20 \%$ (mol).

To simplify the explanation, each initiator system was named by F-system number, for example, the system containing fluorescein without modification was called F-1. The final mixtures containing monomers and initiator system were photopolymerized using the light emission equipment D-2000 (DMC Ltd., São Carlos, SP, Brazil), which uses LED to emit blue light in the $430-490 \mathrm{~nm}$ range, as specified by the manufacturer. The mixtures were placed in a Teflon mold of $1.5 \mathrm{~mm}$ in depth and $3.0 \mathrm{~mm}$ in diameter, and were polymerized for $470 \mathrm{~s}$. After that, the cured polymers underwent thermal analysis.

\subsection{Sample characterization}

2.3.1. Thermogravimetry- Differential Thermal Analysis (TG-DTA), and Derivative Thermogravimetry (DTG)

Simultaneous TG-DTA curves for each polymer were obtained using the thermal analysis system from Netzsch, model STA 449 F3. Approximately $10 \mathrm{mg}$ of sample were measured and placed in a $70 \mu \mathrm{L} \alpha$-alumina open crucible. The parameters were set at a heating rate of $10.0^{\circ} \mathrm{C} \mathrm{min}^{-1}$, and a flow rate of $50.0 \mathrm{~mL} \mathrm{~min}^{-1}$ in a dry air atmosphere. The temperature range was from $30.0^{\circ} \mathrm{C}$ to $800.0^{\circ} \mathrm{C}$.

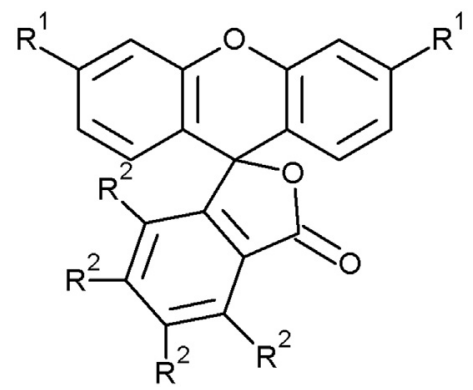

$$
\begin{aligned}
& \mathrm{F} 1, \mathrm{R}_{1}=\mathrm{OH} ; \mathrm{R}_{2}=\mathrm{H} \\
& \mathrm{F} 2, \mathrm{R}_{1}=\mathrm{OH} ; \mathrm{R}_{2}=\mathrm{Cl} \\
& \mathrm{F} 3, \mathrm{R}_{1}=\mathrm{OH} ; \mathrm{R}_{2}=\mathrm{Br} \\
& \mathrm{F} 4, \mathrm{R}_{1}=\mathrm{OMe} ; \mathrm{R}_{2}=\mathrm{H} \\
& \mathrm{F} 5, \mathrm{R}_{1}=\mathrm{OMe} ; \mathrm{R}_{2}=\mathrm{Cl} \\
& \mathrm{F} 6, \mathrm{R}_{1}=\mathrm{OMe} ; \mathrm{R}_{2}=\mathrm{Br}
\end{aligned}
$$

Fig. 2. Chemical structure of fluorescein and its derivatives.

\subsubsection{Differential Scanning Calorimetry (DSC)}

DSC curves for each polymer were obtained with a MettlerToledo DSC1 Star ${ }^{\mathrm{e}}$ system. Approximately $10 \mathrm{mg}$ of sample were placed in a $40 \mu \mathrm{L}$ closed aluminum crucible with perforated lid. The heating rate was $10^{\circ} \mathrm{Cmin}^{-1}$, and the flow rate was $50 \mathrm{~mL}$ $\mathrm{min}^{-1}$. Dry air atmosphere used was. The temperature range was from $150.0^{\circ} \mathrm{C}$ to $220.0^{\circ} \mathrm{C}$. Using the thermal events observed in DSC curves, the degree of conversion (DC) was calculated. It is known that the $\mathrm{C}=\mathrm{C}$ bond requires $60 \mathrm{~kJ} \mathrm{~mol}^{-1}$ to cleave the $\pi$ ligation, which is considered the standard enthalpy of polymerization $\left(\Delta H_{p o l}\right)$ [18-21], and the energy obtained in polymerization peak DSC curves of polymers refers to residual monomer in photopolymerization $\left(E_{p}\right)$. Then, the DC (\%) can be obtained from DSC curves using Eq. (1).

$D C(\%)=\left[1-\left(\frac{E_{p} \cdot M M}{\Delta H_{p o l} \cdot m_{a}}\right)\right] \times 100$

Formula to calculate the percent of degree of conversion (DC) using the DSC.

The MM is the molar mass of monomer, and $m_{a}$ is the sample mass used in DSC analysis.

\subsubsection{Middle Infrared Spectroscopy (MIR)}

To calculate the degree of conversion for each polymer, a spectrophotometer from Bruker, model Vertex 70, was used. The equipment operated in the range $4000-400 \mathrm{~cm}^{-1}$. Monomeric mixtures were placed over the diamond crystal and polymerized while the transmittance (T\%) of each sample was collected. Data collection occurred every $10 \mathrm{~s}$, and 47 measurements were made for all samples. Eq. (2) was used to quantify the degree of conversion for each sample [22].

$D 1(\%)=\left[1-\frac{T_{t=0}(\mathrm{CC})}{T_{t=x}(\mathrm{CC})}\right] \times(-1000)$

Formula to calculate the percent of degree of conversion (DC) using the transmittance of double carbon bonds $(C=C)$ present in the monomer.

Transmittance of the $\mathrm{C}=\mathrm{C}$ bond can be observed near the wavenumber $1640 \mathrm{~cm}^{-1}$. At the initial time $(t=0)$, a minimum of transmittance is observed at this wave number, as polymerization has not yet begun. At any other future time $(t=x)$, the transmittance increases, as polymerization takes place and double bonds are cleaved. With this input of data and applying Eq. (2), graphs of degree of conversion over time were plotted.

\subsubsection{Scanning Electronic Microscopy (SEM)}

To study the morphology of the polymer, an EVO LS15 scanning electronic microscope from Zeiss was used. Preparation of the samples involved powdering them, placing them over a carbon 
Table 1

Luminescent proprieties of dyes: maximum absorbance $\left(\lambda_{\mathrm{abs}}\right)$, maximum emission $\left(\lambda_{\text {em }}\right)$, Stokes shift $(\Delta v)$, molar absorption coefficients $(\varepsilon)$ and quantum yields $\left(\phi_{\mathrm{f}}\right)$ [14].

\begin{tabular}{llllll}
\hline Dye & $\lambda$ abs $(\mathrm{nm})$ & $\lambda$ em $(\mathrm{nm})$ & $\Delta \mathrm{v}(\mathrm{nm})$ & $\varepsilon\left(\mathrm{L} . M^{-1} \mathrm{~cm}^{-1}\right)$ & $\phi_{\mathrm{f}}$ \\
\hline F-1 & 491 & 515 & 24 & $1.1 \times 10^{5}$ & 0.93 \\
F-2 & 511 & 525 & 14 & $5.0 \times 10^{4}$ & 0.75 \\
F-3 & 512 & 525 & 13 & $5.7 \times 10^{4}$ & 0.72 \\
F-4 & 479 & 515 & 39 & $2.7 \times 10^{3}$ & 0.63 \\
F-5 & 507 & 525 & 29 & $7.4 \times 10^{3}$ & 0.78 \\
F-6 & 507 & 525 & 29 & $3.4 \times 10^{4}$ & 0.60 \\
\hline
\end{tabular}

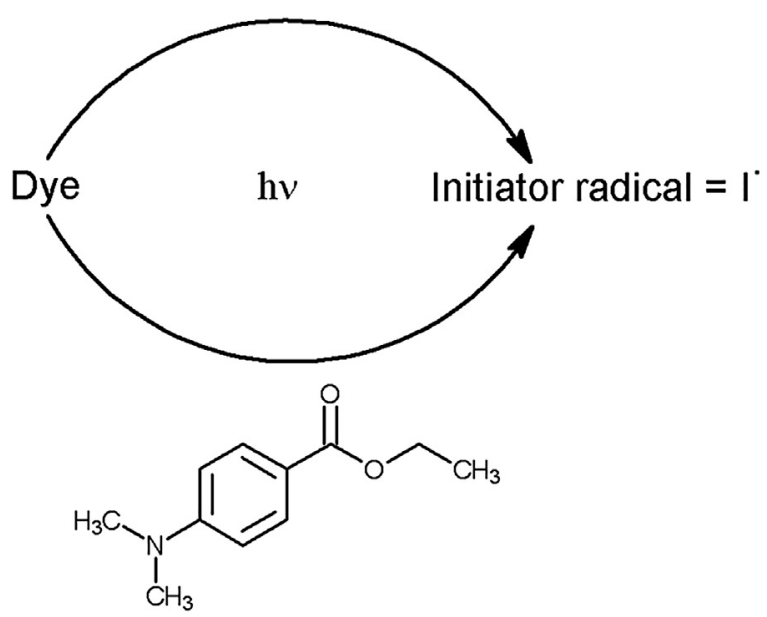

Fig. 3. Mechanism for formation initiators.

adhesive, and finally plating them with gold. The voltage was set at $15 \mathrm{kV}$, and the samples were magnified 300 times in a low-pressure environment $\left(10^{-3} \mathrm{~Pa}\right)$.

\section{Results and discussion}

\subsection{Photopolymerization}

The reaction was initiated with free radical photoinitiators. The dyes absorbed light in the spectrum of 476-512 nm (Table 1 shows all the fluorescence proprieties of each dye), reaching an excited state and withdrawing a hydrogen atom $\left(\mathrm{H}^{\bullet}\right)$ from the tertiary amine, to produce a primary radical $\left(\mathrm{I}^{\bullet}\right)$. Furthermore, the radical is formed in the dye, and this radical may participate in the polymerization propagation. Fig. 3 shows the mechanism of initiator formation by light.

The radical triggers the homolytic cleavage in $\pi$ bonds $(C=C)$ on dimethacrylate monomers, which produces new radicals (propagation step) [23-25]. Two different radicals might be formed, a tertiary one [more stable (A), Fig. 4-a] or a primary one [less stable (B), Fig. 4-a], both of which can initiate and propagate the polymerization (Fig. 4-b).

The termination step of polymerization may have occurred according to two reaction processes in the polymer. In the first process, a bond between the radical UDMA and the radical initiator may have formed, similar to the termination step. The second process may have involved the formation of a bond between two radicals present in neighboring UDMA molecules (Fig. 4-b).

\subsection{Thermogravimetry- Differential Thermal Analysis (TG-DTA) and first derivate of TG curve (DTG)}

The TG/DTG-DTA curves of the composites are presented simultaneously in Fig. 5. The DTG was applied to obtain the thermal steps (to understand better) and the maximum degradation rate of the first step in all samples. Table 2 summarizes these findings. Each polymer has four steps of mass loss: the first indicates the volatilization of the solvent and the other three remaining steps indicate its thermal degradation (related with exothermic events in DTA). The average thermal stability for the samples was $193.1{ }^{\circ} \mathrm{C}$, with a standard deviation (SD) of 7.9. The small value of SD indicates that the different dyes had little effect on the thermal stability of the samples. Another factor that did not modify was the residual mass (carbonaceous matter not degraded); hence, it was possible to calculate this content, which had an average value of $1.32 \%$. The moisture content displayed no big difference in the samples, with an average moisture of $2.44 \%$ and $\mathrm{SD}=1.35$. The maximum degradation rates for polymers using initiator system with different dyes (F-1 to F-6) were $8.73 \% \mathrm{~min}^{-1}$, $7.64 \% \mathrm{~min}^{-1}, \quad 6.59 \% \mathrm{~min}^{-1}, \quad 7.89 \% \mathrm{~min}^{-1}, \quad 7.77 \% \mathrm{~min}^{-1}$, and $7.09 \% \mathrm{~min}^{-1}$, respectively. The only difference observed in $\mathrm{F}-3$ and F-6 DTA curves was an exothermic peak at $184.8^{\circ} \mathrm{C}$ and $183.9^{\circ} \mathrm{C}$ due to monomer polymerization [26].
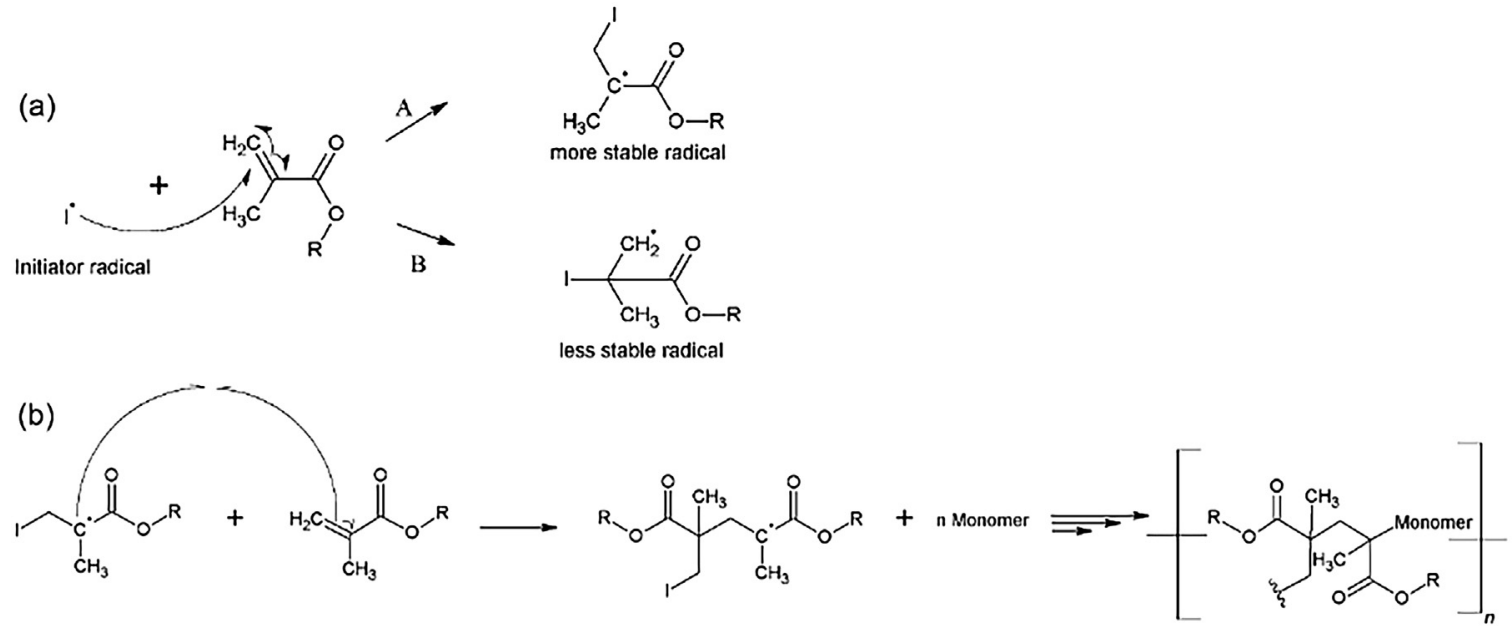

Fig. 4. Reaction mechanism: production of new radicals (a); and propagation and termination in UDMA (b). 

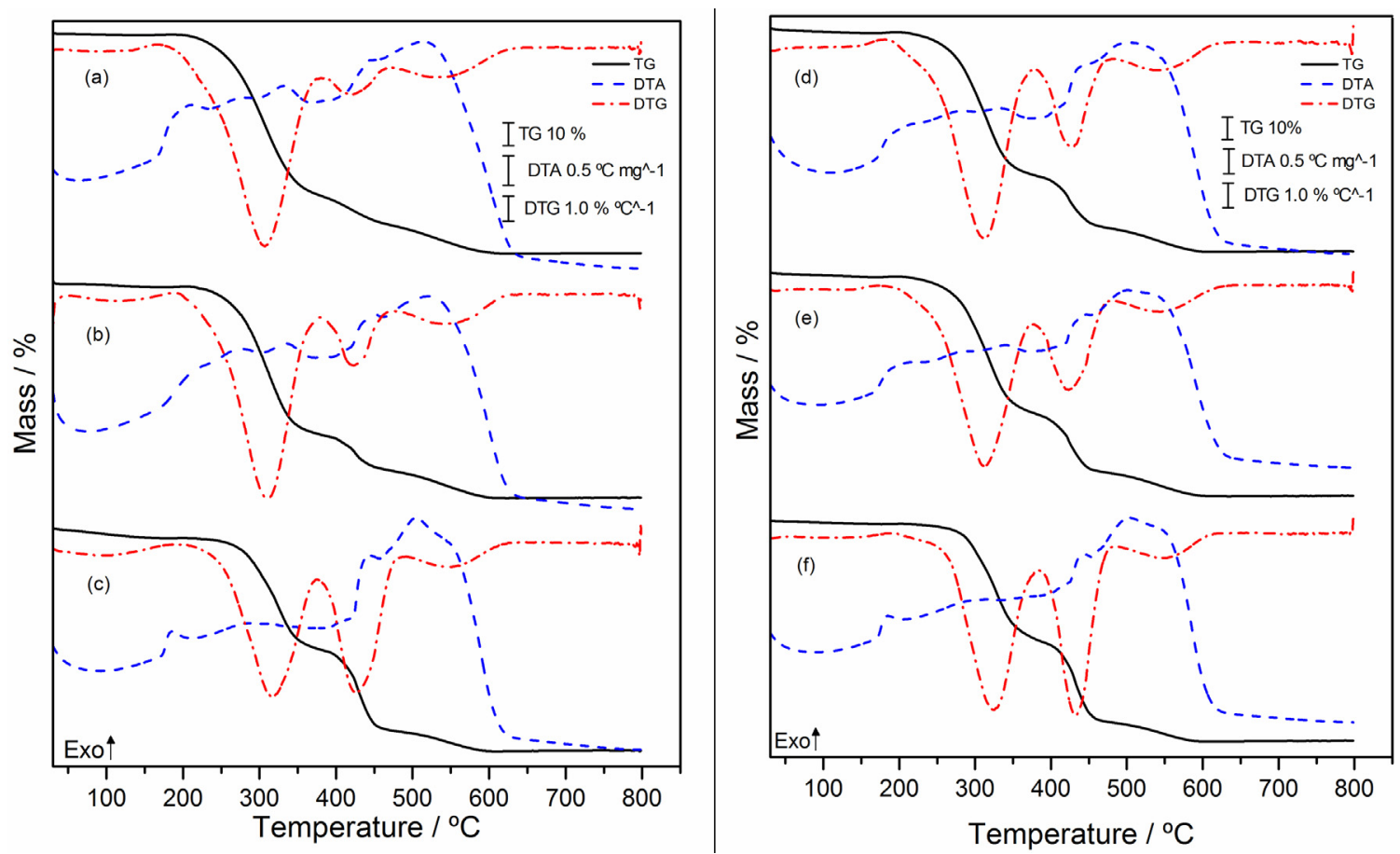

Fig. 5. TG-DTA/DTG curves for F-1 (a), F-2 (b), F-3 (c), F-4 (d), F-5 (e), and F-6 (f).

Table 2

Summary of polymers' mass loss events $(\Delta \mathrm{m} / \%)$, the temperature range in which each event occurred $\left(\theta^{\circ} \mathrm{C}\right)$, and the temperature peak ( $\left.\mathrm{T}_{\mathrm{P}} /{ }^{\circ} \mathrm{C}\right)$ are also given.

\begin{tabular}{|c|c|c|c|c|c|}
\hline \multicolumn{2}{|c|}{ Initiator System } & \multirow{2}{*}{$\begin{array}{l}\text { Volatilization Step } \\
30.0-180.6\end{array}$} & \multirow{2}{*}{$\begin{array}{l}\text { 1st decomposition Step } \\
188.2-380.8\end{array}$} & \multirow{2}{*}{$\frac{\text { 2nd decomposition Step }}{380.8-473.4}$} & \multirow{2}{*}{$\begin{array}{l}\text { 3th decomposition Step } \\
473.4-652.6\end{array}$} \\
\hline $\mathrm{F}-1$ & $\theta \circ \mathrm{C}$ & & & & \\
\hline & loss $/ \%$ & 0.89 & 70.91 & 12.95 & 12.37 \\
\hline & Peak $/{ }^{\circ} \mathrm{C}$ & - & $210.8 \uparrow ; 244.5-300.8^{*} ; 331.6 \uparrow$ & $442.8 \uparrow$ & $511.6 \uparrow$ \\
\hline \multirow[t]{3}{*}{$\mathrm{F}-2$} & $\theta \circ \mathrm{C}$ & $30.0-187.7$ & $187.7-379.7$ & $379.7-473.3$ & $473.3-637.7$ \\
\hline & loss $/ \%$ & 3.44 & 64.88 & 15.84 & 11.99 \\
\hline & Peak $/{ }^{\circ} \mathrm{C}$ & - & $252.0-303.1^{*} ; 334.3 \uparrow$ & $420.3-445.9^{*} ; 452.7 \uparrow$ & $522.5 \uparrow$ \\
\hline \multirow[t]{3}{*}{$\mathrm{F}-3$} & $\theta \circ \mathrm{C}$ & $30.0-203.4$ & $203.4-376.0$ & $376.0-488.5$ & $488.5-642.0$ \\
\hline & loss $/ \%$ & 4.61 & 48.62 & 36.64 & 8.29 \\
\hline & Peak $/{ }^{\circ} \mathrm{C}$ & - & $251.0-354.9^{*}$ & $441.4 \uparrow$ & $504.7 \uparrow$ \\
\hline \multirow[t]{3}{*}{$\mathrm{F}-4$} & $\theta \circ \mathrm{C}$ & $30.0-188.0$ & $188.0-378.8$ & $376.0-483.8$ & $483.8-636.3$ \\
\hline & loss $/ \%$ & 2.14 & 63.40 & 23.82 & 10.11 \\
\hline & Peak $/{ }^{\circ} \mathrm{C}$ & - & $256.8-305.4^{*} ; 315.9-365.5^{*}$ & $421.7-457.0^{*}$ & $504.9 \uparrow$ \\
\hline \multirow[t]{3}{*}{ F-5 } & $\theta \circ \mathrm{C}$ & $30.0-188.0$ & $188.0-375.0$ & $375.0-482.8$ & $482.8-647.7$ \\
\hline & loss $/ \%$ & 2.01 & 60.32 & 26.99 & 10.06 \\
\hline & Peak $/{ }^{\circ} \mathrm{C}$ & - & $190.0-236.7^{*} ; 262.5-306.4^{*} ; 339.9 \uparrow$ & $419.9-439.8^{*} ; 447.5 \uparrow$ & $502.1 \uparrow$ \\
\hline \multirow[t]{3}{*}{ F-6 } & $\theta^{\circ} \mathrm{C}$ & $30.0-209.0$ & $203.5-384.5$ & $384.5-485.6$ & 485.6-634-5 \\
\hline & loss $/ \%$ & 1.57 & 51.77 & 36.47 & 8.19 \\
\hline & Peak $/{ }^{\circ} \mathrm{C}$ & - & $257.7-336.8^{*}$ & $402.6-423.6^{*} ; 440.8 \uparrow$ & $502.4 \uparrow$ \\
\hline
\end{tabular}

$\uparrow=$ Exothermic peak; ${ }^{*}=$ Exotherm.

In conclusion, the initiator system of the dyes does not affect the moisture content, thermal stability, residual matter, and mass loss steps. The details of the thermal steps for all the samples are shown in Table 2.

\subsection{Degree of conversion}

\subsubsection{Middle Infrared Spectroscopy (MIR)}

The MIR measurements depicted a band near $1640 \mathrm{~cm}^{-1}$, evincing the $\mathrm{C}=\mathrm{C}$ double bond present in the dimethacrylate molecules. As expected, the intensity of this band decreased considerably for the polymers, because this process involves the cleavage of the $\pi$ bond. Hence, it was possible to calculate the degree of conversion for each monomer using Eq. (2). Table 3 and Fig. 6 show the degree of conversion at different times during polymerization for all six monomeric mixtures studied.

The F-1 system (standard fluorescein) had lower conversion in the first $20 \mathrm{~s}(0.87 \%)$, and after $200 \mathrm{~s}$, over half the monomers were converted $(52.70 \%)$. At $470 \mathrm{~s}$, there was a total conversion of $75.59 \%$, which is a very good result in cross-linked polymers.

In the F-2 system (Chlorinated fluorescein), the same conversion as F-1 was observed in the first $10 \mathrm{~s}(0.86 \%)$. However, after 20 s, $5.61 \%$ conversion was obtained, which is higher than $\mathrm{F}-1$, and a baseline line 


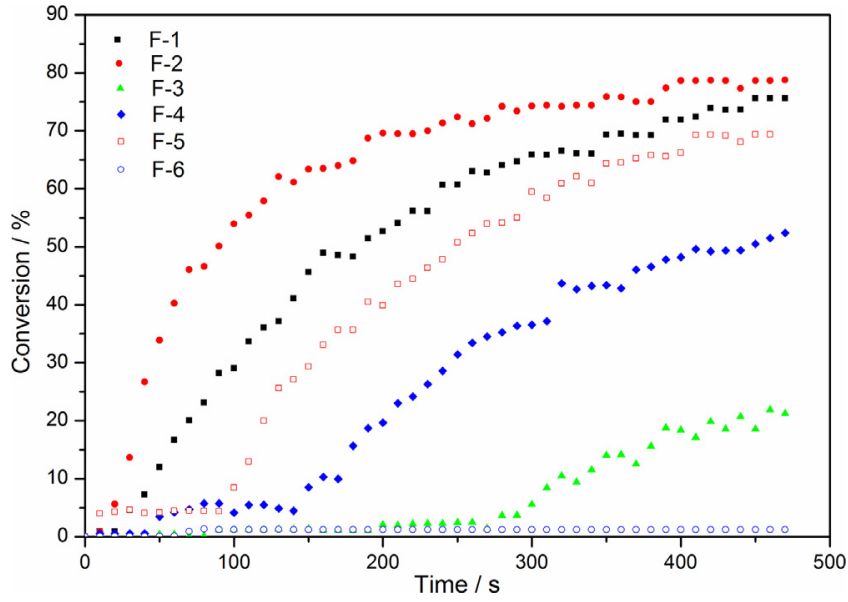

Fig. 6. Conversion degree curves for polymers F-1 to F-6. was observed at $350 \mathrm{~s}$ (75.86\%). The F-2 system showed great conversion (78.73\%), higher than standard fluorescein, this could be explained due to chlorine atoms in the structure, which form the excited triplet state in the dye, promote radical formation, and consequently faster polymerization reaction $[27,28]$.

The F-3 system did not have good conversion, just $0.36 \%$ in the first $50 \mathrm{~s}$, and $21.18 \%$ of total conversion. This variance was explained due to the chemical structure of the dye, which has Bromine. It is known that bromine stabilizes radicals, thus it could stabilize radical generated from any process, due to the ability to put an electron in its electro sphere, consequently these radicals do not cleave the $\pi$ bond on the monomers $(C=C)$. For this propriety, the brominated compounds are widely used in antioxidants and flame retardants [29-35].

The F- 4 system had a low conversion at $100 \mathrm{~s}$ (4.10\%), and a total conversion of $52.36 \%$, which is slightly over half. This system had a lower conversion than F-1; both had no halogen in the structure. On the other hand, the F-5 system had conversion as good as the F1 system, with a fast conversion in the first $10 \mathrm{~s}$ (3.96\%) and a total conversion of $69.36 \%$ in $470 \mathrm{~s}$. This good conversion was related to chlorine atoms in the dye structure that promote radical similar to the F-2 system. Finally, the F-6 system had poor conversion, just $1.21 \%$ after $470 \mathrm{~s}$, due to bromine in the dye structure and low light excitation. In this case, MIR measurement was not sensitive enough to obtain double bond variation.

Table 3

Conversion degree (\%) of monomers to polymers with different initiators systems.

\begin{tabular}{|c|c|c|c|c|c|c|c|c|}
\hline Initiator System & $10 \mathrm{~s}$ & $\begin{array}{l}20 \\
\text { seconds }\end{array}$ & $\begin{array}{l}50 \\
\text { Seconds }\end{array}$ & $\begin{array}{l}100 \\
\text { seconds }\end{array}$ & $200 \mathrm{~s}$ & $350 \mathrm{~s}$ & $470 \mathrm{~s}$ & Total DC by DSC \\
\hline F-1 & $0.86 \%$ & $0.87 \%$ & $11.99 \%$ & $29.01 \%$ & $52.70 \%$ & $69.34 \%$ & $75.59 \%$ & $69.67 \%$ \\
\hline $\mathrm{F}-2$ & $0.86 \%$ & $5.61 \%$ & $33.86 \%$ & $53.94 \%$ & $69.60 \%$ & $75.86 \%$ & $78.73 \%$ & $82.84 \%$ \\
\hline F-3 & $0.38 \%$ & $0.36 \%$ & $0.36 \%$ & $1.19 \%$ & $2.03 \%$ & $13.96 \%$ & $21.18 \%$ & $25.77 \%$ \\
\hline $\mathrm{F}-4$ & $0.54 \%$ & $0.54 \%$ & $3.44 \%$ & $4.10 \%$ & $19.66 \%$ & $43.37 \%$ & $52.36 \%$ & $68.96 \%$ \\
\hline F-5 & $3.96 \%$ & $4.26 \%$ & $4.14 \%$ & $8.45 \%$ & $39.89 \%$ & $64.34 \%$ & $69.36 \%$ & $68.55 \%$ \\
\hline F-6 & $0.03 \%$ & $0.03 \%$ & $0.04 \%$ & $1.21 \%$ & $1.21 \%$ & $1.21 \%$ & $1.21 \%$ & - \\
\hline
\end{tabular}

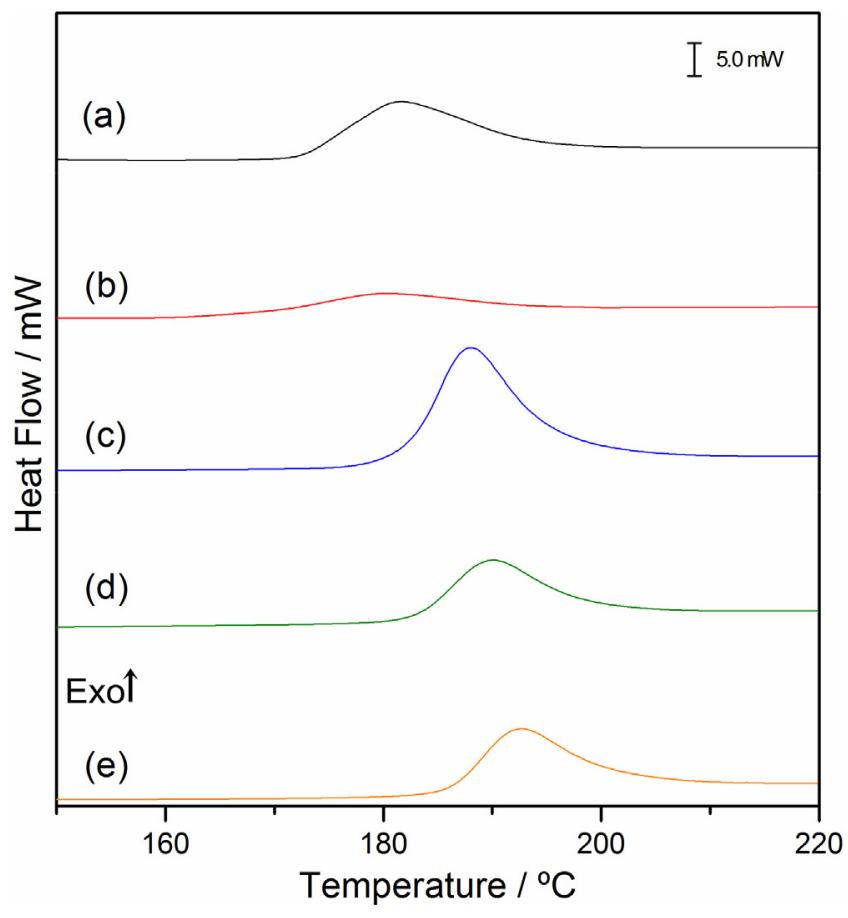

Fig. 7. DSC curves for F-1 (a), F-2 (b), F-3 (c), F-4 (d), and F-5 (e).

\subsubsection{Differential Scanning Calorimetry (DSC)}

The DSC curves are shown in Fig. 7. All systems had a similar thermal behavior: an exothermic peak associated to polymerization of residual monomers in photopolymerization. The F- 1 system (7-a) had an exothermic peak at $181.5^{\circ} \mathrm{C}$ and an energy associated to event $\left(E_{p}\right)$ equals $525.09 \mathrm{~mJ}$, using Eq. (2), in which the DC obtained in photopolymerization was 69.67\%. The F-2 system (7-b) showed the thermal polymerization peak at $179.95^{\circ} \mathrm{C}$ and $\mathrm{E}_{\mathrm{p}}=285.3 \mathrm{~mJ}$; the DC obtained was $82.84 \%$. The curve $7-\mathrm{c}$ is associated to the F3 system which presented the polymerization peak at $188.0^{\circ} \mathrm{C}, \mathrm{E}_{\mathrm{p}}=1092.13$ and $\mathrm{DC}=25.77 \%$. The $\mathrm{F}-4$ and $\mathrm{F} 5$ systems can be viewed in Fig. 7-d and -e, respectively. The F-4 system had a peak polymerization at 189.98 , with $\mathrm{E}_{\mathrm{p}}=616.34 \mathrm{~mJ}$ involved in process and $\mathrm{DC}=68.96 \%$. The data obtained for the F-5 system were thermal polymerization at $192.55^{\circ} \mathrm{C}$ and $\mathrm{E}_{\mathrm{p}}=591.84$ $\mathrm{mJ}$, resulting in $\mathrm{DC}=68.55 \%$ photopolymerization. The F- 6 system was not considered in DSC analyses because the DC results from the MIR found an insignificant conversion (1.21\%); thus, this system was considered just UDMA monomers, not a polymer. All conversion data by DSC analysis are in Table 3.

The values of DC obtained from DSC curves showed minimal variance compared with values from MIR and are considered good results. The difference between the values could be associated to higher sensitivity of DSC. Notwithstanding, the F-1, F-2, F-4, and F5 systems showed close or higher conversions when compared with the standard system, which uses Camphorquinone dye (CQ) 

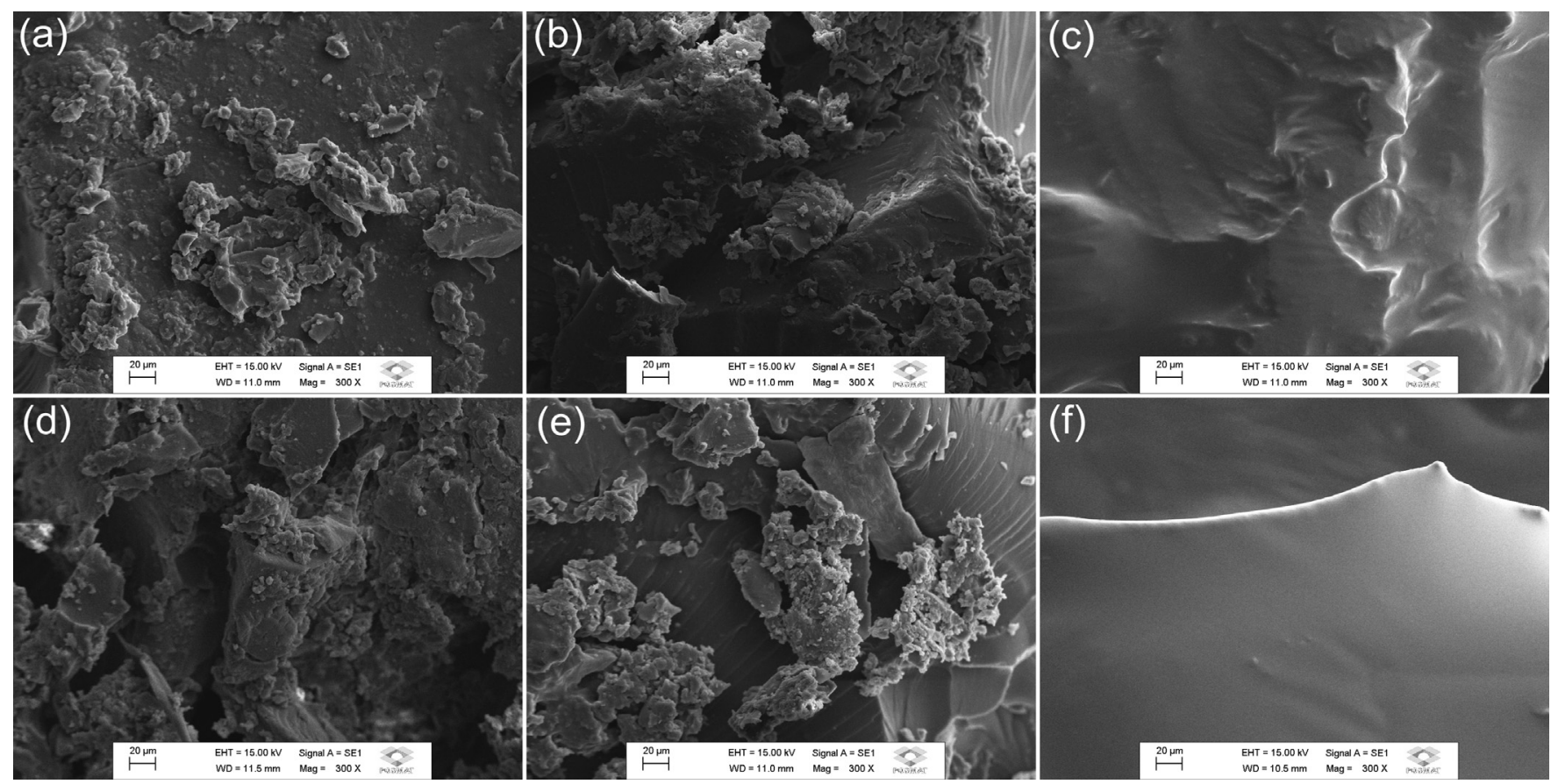

Fig. 8. SEM analysis at magnification of $300 x$ for F-1 (a), F-2 (b), F-3 (c), F-4 (d), F-5 (e), and F-6 (f).

as initiator. This standard system has a conversion of about $69-80 \%$ in UDMA monomer [36-39].

\subsection{Scanning Electronic Microscopy (SEM)}

Polymers F-1, F-2, F-4, and F-5 had the same morphology, all were solid rigid and showed fractures due to maceration, which prove hardness. However, polymer F-3 showed no hardness, but a gelatinous aspect, due to low conversion to polymers. This indicates a high quantity of monomers in the cross-linked polymer, which was also evident in F-6 that had the lowest conversion. Images of morphology (amplified 300 times) of all the polymers are shown in Fig. 8.

\section{Conclusions}

The use of fluorescein as a photoinitiator in the polymerization of urethane dimethacrylate (UDMA) proved to be effective, with a conversion of $75.79 \%$. Furthermore, the chlorinated dyes exhibited good results. The F-2 system had a higher conversion than standard fluorescein (F-1 system), and the F-5 system had a conversion of $69.36 \%$, which could be due to chlorine atoms in the structure that facilitate the excited triplet state. However, brominated dyes (F-3 and F-6) produced low conversion ( $21.18 \%$ and $1.21 \%$, respectively), attributed to bromine atoms in the dye structure, which stabilize radicals. Similar degree of conversion was obtained using DSC analysis, which presented a higher sensibility than MIR. The TGDTA/DTG curves showed that polymers with different systems (F$1-\mathrm{F}-6)$ had an average stability at $193.9^{\circ} \mathrm{C} \pm 7.9$. However, the different initiator systems did not modify the thermal stability of the polymers or their thermal degradation steps.

The SEM images shown that systems F-1, F-2, F-4, and F-5 had similar morphology, which was solid rigid with fractures, proving hardness. On the other hand, the F-3 and F-6 systems exhibited gelatinous aspects, due to low conversion of monomers.

To sum up, the chlorinated dyes (F-2 and F-5) are promising for photoinitiators, with higher conversion than the standard system, which is currently widely used (Camphorquinone/tertiary amine).
However, brominated dyes should be investigated for other applications, such as flame-retardants or antioxidants.

\section{Acknowledgements}

The authors wish to thank CAPES (proc. 024/2012 Proequipment), POSMAT/UNESP, and FAPESP (processes: 2012/ 21450-1, 2013/09022-7, 2014/01337-1 and 2016/01599-1) for financial support.

\section{References}

[1] J.P. Fouassier, X. Allonas, D. Burget, Photopolymerization reactions under visible lights: principle, mechanisms and examples of applications, Prog. Org. Coat. 47 (2003) 16-36.

[2] J. Jakubiak, J. Nie, L.A. Línden, J.F. Rabek, Crosslinking photocopolymerization of acrylic acid (and N-vinylpyrrolidone) with triethylene glycol dimethacrylate initiated by camphorquinone/ethyl-4-dimethylaminobenzoate, J. Polym. Sci. Pol. Chem. 38 (2000) 876-886.

[3] H. Lu, L.G. Lovell, C.N. Bowman, Exploiting the heterogeneity of cross-linked photopolymers to create high-Tg polymers from polymerizations performed at ambient conditions, Macromolecules 34 (2001) 8021-8025.

[4] O. Ye, P. Spencer, Y. Wang, A. Misra, Relationship of solvent to the photopolymerization process, properties, and structure in model dentin adhesives, J. Biomater. Mat. Res. 80 (2007) 342-350.

[5] M.R. Rodrigues, M.G. Neumann, Fotopolimerização: princípios e métodos, Pol. Cienc. Tecnol. 13 (2003) 276-286.

[6] K.S. Lim, B.J. Schon, N.V. Mekhileri, G.C.J. Brown, C.M. Chia, S. Prabakar, G.J. Hooper, T.B.F. Woodfield, New visible-light photoinitiating system for improved print fidelity in gelatin-based bioinks, Biomater. Sci. Eng. 10 (2016) 1752-1762.

[7] N.S. Allen, Photoiniators for UV and visible curing of coatings: mechanisms and properties, J. Photochem. Photobiol. A: Chem. 100 (1996) 101-107.

[8] J. Zhao, J. Lalevée, H. Lu, R. MacQueen, S.H. Kable, T.W. Schmidt, M.H. Stenzel, P. Xiao, A new role of curcumin: as a multicolor photoinitiador for polymer fabrication under household UV to red LED bulbs, Polym. Chem. 6 (2015) 5053-5062.

[9] J. Lalevée, J.P. Fouassier, Dyes and Chromophores in Polymer Science, first ed., Wiley-John Wiley \& Sons, Weinhein, 2015.

[10] J.P. Fouassier, J. Lalevée, Photoinitiators for Polymer Systhesis: Scope, Reactivity and Efficiency, first ed., Wiley-VCH Verlag Gmbh \& Co KGaA Weinhein, 2012.

[11] M.M. Martin, L. Lindqvist, The pH dependence of fluorescein fluorescence, J. Lumin. 10 (1975) 381-390.

[12] H. Diehl, R. Markuszewski, Studies on fluorescence VII: the fluorescence of fluorescein as a function of pH, Talanta 36 (1989) 416-418. 
[13] R. Sjöback, J. Nygren, M. Kubista, Absorption and fluorescence properties of fluorescein, Spectrochim. Acta 51 (1995) L7-L21.

[14] B.H.S.T. Silva, B.A. Bregadiolli, C.F.O. Graeff, L.C. da Silva-Filho, $\mathrm{NbCl}_{5}$-promoted synthesis of novel fluorescein dye derivatives: spectroscopic and spectrometric characterization and its application in dye-sensitized solar cells, ChemPlusChem . 82 (2017) 261-269.

[15] L.P. Icart, E. Fernandes, L. Agüero, J. Ramón, D. Zaldivar, M.L. Dias, Fluorescent microspheres of poly(ethylene glycol)-poly(lactic acid)-fluorescein copolymers synthetized by Ugi four-component condensation, J. Appl. Polym. Sci. 133 (2016) 1-9.

[16] Y. Pang, M.K. Sarvothaman, H. Ritter, Novel of Synthetic routes sysnthesis of 5 (methacryloylamino)-fluorescein and fluorescet polymers using 5-MAF as fluorescent marker, J. Macromol. Sci. 42 (2014) 1013-1024.

[17] B. Wang, X. Guan, Y. Hu, Z. Si, Synthesis and photophysical behavior of a watersoluble fluorescein-bearing polymer for $\mathrm{Fe}^{3+}$ ion sensing, J. Pol. Res. 15 (2008) 427-433.

[18] M.A. Terrin, M.A. Horn, M.G. Neumann, E.T. Cavalheiro, I.C. Correa, C.C. Schimitt, Effect of the loading of organomodified clays on the thermal and mechanical properties of a model dental resin, Mat. Res. 19 (2016) 40-44.

[19] D.E. Roberts, Heats of polymerization: a summary of published values ant their relation structure, U.S. Dep. Commerce Natl. Bur. Stand. 44 (1950) 221-232.

[20] Y. Tanimot, T. Hayakawa, K. Nemoto, Analysis of photopolymerization behavior of UDMA/TEGDMA resin mixture and its composite by Differential Scanning Calorimetry, J. Biomed. 72 (B) (2004) 310-315.

[21] S.V. Canevarolo Junior, Técnicas De Caracterização De Polímeros, first ed., Artliber Editora, São Paulo, 2007.

[22] D.S.B.L. Oliveira, L.S.B.L. Oliveira, R.T. Alarcon, B.B.C. Holanda, G. Bannach, Use of curcumin and glycerol as an effective photoinitiating system in the polymerization of urethane dimethacrylate, J. Therm. Anal. Calorim. (2017), doi:http://dx.doi.org/10.1007/s10973-017-6094-x.

[23] J.P. Fischer, D. Dean, P.S. Engel, A.G. Mikos, Photoinitiated polymerization of biomaterials, Annu. Rev. Mater. Sci. 31 (2001) 171-181.

[24] R. Harikrishna, S. Ponrathnam, C.R. Rajan, S.S. Tambe, Photopolymerization of bis-aromatic and alicyclic based solid urethane acrylate macromonomer in the presence of large excess of reactive diluents, J. Therm. Anal. Calorim. 112 (2013) $805-813$.

[25] J.M. Morancho, A. Cadenato, X. Fernandez-Franco, J.M. Salla, X. Ramis, Isothermal kinetics of photopolymerization and thermal polymerization of Bis-GMA/TEGDMA resins, J. Therm. Anal. Calorim. 95 (2008) 513-522.
[26] T. Hayama, K. Takahashi, K. Kikutake, I. Yokota, K. Nemoto, Analysis of polymerization behavior of dental dimethacrylate monomers by differential scanning calorimetry, J. Oral Sci. 41 (1999) 9-13.

[27] R. Podsiadly, K. Podemska, A.M. Swymczak, Novel visible photoinitiators system for free radical/cationic hybrid photopolymerization, Dyes Pigm. 91 (2011) 422-426.

[28] R. Podsiadly, A.M. Swymczak, K. Podemska, The synthesis of novel, visiblewaveleght, oxidizable polymerization sensitizers based on the 8-halogen-5, 12-dihydroquinoxalino [2, 3-b]quinoxaline skeleton, Dyes Pigm. 82 (2009) 365-371.

[29] K. Podemska, R. Podsiadly, A.M. Swymczak, J. Sokolowska, Diazobenzo[a] fluorine derivatives as visible photosensitizers for free radical polymerization, Dyes Pigm. 94 (2012) 113-119.

[30] F. Rahman, K.H. Langford, M.D. Scrimshaw, J.N. Lester, Polybrominated diphenyl ether (PBDE) flame retardants, Sci. Total Environ. 275 (2001) 1-17.

[31] C.A. Wit, An overview of brominated flame retardants in the environment, Chemosphere 46 (2002) 583-624.

[32] Z. Guo, S. Ran, Z. Fang, Smoke suppression of graphene platelets fabricated by Friedel-Crafts reaction in brominated flame-retarded PS, J. Therm. Anal. Calorim. (2017), doi:http://dx.doi.org/10.1007/s10973-017-6093-y.

[33] A. Covaci, S. Harrad, M.A.E. Abdallah, N. Ali, R.J. Law, D. Herzke, C.A. Wit, Nove brominated flame retardants: a review of their analysis, environmental fate and behavior, Environ. Int. 37 (2011) 532-556.

[34] I. Watanabe, S.I. Sakai, Enviromental release and behavior of brominated flame retardants, Environ. Int. 29 (2003) 665-682

[35] M. Alaee, P. Arias, A. Sjodin, A. Bergman, An overview of commercially used brominated flame retardants, their applications, their use patterns in different countries/regions and possible modes of release, Environ. Int. 29 (2003) 683689.

[36] V.E.S. Gajewski, C.S. Pfeifer, N.R.G. Fróes-Salgado, L.C.C. Boaro, R.R. Braga, Monomers used in resin composites: degree of conversion, mechanical properties and water sorption/solubility, Braz. Dent. J. 23 (2012) 508-514.

[37] I.D. Siderou, D.S. Achilias, Elution study of unreacted Bis-GMA, TEGDMA UDMA and Bis-EMA from light-cured dental resins and resin composites using HPLC, Interscience 74 (2004) 617-626.

[38] I. Siderou, V. Tserki, G. Papanastasiou, Effect of chemical structure on degree of conversion in light-cured dimethacrylate-based dental resins, Biomaterials 23 (2002) 1819-1829.

[39] R.M. Guerra, I. Durán, P. Ortiz, FTIR monomer conversion analysis of UDMAbased dental resins, J. Oral. Rehabil. 23 (1996) 632-637. 